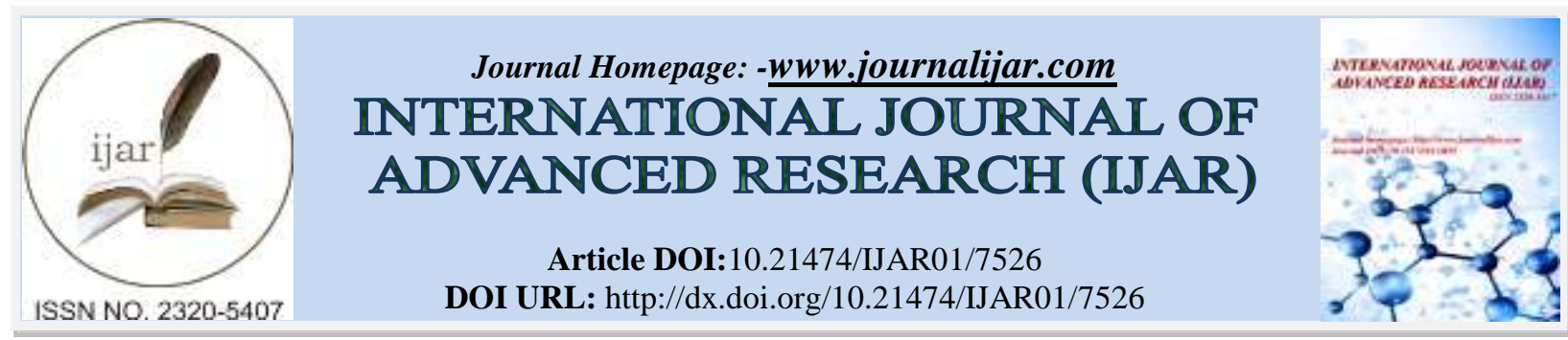

RESEARCH ARTICLE

\title{
COGNITIVE BEHAVIORAL THERAPY (CBT) VS RELAXATION THERAPY(RT) ON FATIGUE AMONG TEACHING PROFESSIONALS WITH CHRONIC FATIGUE SYNDROME - PILOT STUDY REPORT.
}

\author{
Prof.J.Kavin mozhi ${ }^{1}$, Dr. C. Susila ${ }^{2}$ and Dr. R. Rajkumar ${ }^{3}$. \\ 1. P.hD, Research scholar, Meenakshi Academy of Higher Education and Research,Chennai, Tamil Nadu. \\ 2. Principal, Billroth College of Nursing, Chennai, Tamil Nadu. \\ 3. Professor\&Colposcopist, Meenakshi Medical College, Research Insttitue,Kancheepuram.
}

(.........................

Manuscript History

Received: 10 June 2018

Final Accepted: 12 July 2018

Published: August 2018

Keywords:-

Teaching professionals with chronic fatigue syndrome, Cognitive behavioral therapy, relaxation therapy, fatigue

\section{Manuscript Info}

\begin{abstract}
Objectives: To compare the effectiveness of CBT and RT on fatigue among teaching professionals with CFS.

Method: Quasi experimental with time series design was adopted. The study was conducted at selected schools in chennai. 30 samples who fulfilled the inclusive criteria were included in this study using non probability convenient sampling technique. Fatigue severity scale was used for data collection.Results: The mean difference score of fatigue had significant values, showed the effectiveness of cognitive behavioral therapy and relaxation therapy. The reliability of the tool was measured by test and retest method. Conclusion: the pilot study revealed the data collection tools were reliable and practicable to carry out the main study. There is significant improvement in fatigue in both CBT group and RT group when compared with control group. When compared to RT, CBT shows better improvement in fatigue .
\end{abstract}

Copy Right, IJAR, 2018,. All rights reserved.

\section{Introduction:-}

Fatigue is inevitable when we do any sort of activity or some time even at rest. When fatigue accumulates for prolonged period leads to chronic fatigue .In our busy life style we ignore that we are growing fatigued -- in bad mood, loosing ability to pay close attention, having little patience with people, without realizing that we are ending up with the condition called chronic fatigue syndrome. According to Center for Disease Control and Prevention , Chronic fatigue syndrome (CFS) is essentially a very debilitating and complex disorder characterized by profound fatigue that is not improved by bed rest and that may be worsened by physical or mental activity. Symptoms may include weakness, muscles pain, impaired memory, and/ or mental concentration and insomnia, which can affect several body system (2).Despite 20 years of research and over 3000 published peer reviewed papers, the etiology of CFS remains unclear.(5). Researchers have not yet identified the exact cause for CFS, and there are no definite tests to diagnose. $(1,2,4)$

This condition can be seen in every profession especially health care, Information technology and teaching. Teaching when done properly, is physically, mentally and emotionally exhausting. Demanding workloads and extensive job duties in and beyond the class room have pressured teachers into a state of mental and physical exhaustion leads to fatigue and chronic fatigue syndrome. Furthermore CFS among teachers may result in health hazards and long term absence from work, leading to loss of productivity and quality of life. 
Worldwide average prevalence of CFS was 1.2\%(2011).Institute of medicine (IOM )report(2015) says 8,36,000 to million suffer from CFS but most of them not been diagnosed. One of the U.S report says CFS reduced the workforce productivity by $54 \%$ leading to 9.1 billion dollars of total productivity loss.(4) There is no real population study in India. Whatever may be the ratio of prevalence, the total number of person suffering from CFS in hugely populated India must be very large. Only few people with CFS seek professional help for its treatment in early stage itself. If left untreated, CFS is unremitting associated with substantial reduction in occupational, personal and social status. There is no exact treatment option for CFS but Research studies shows promising improvement with psychotherapeutic measures like cognitive behavioral therapy and relaxation therapy. Both may help alleviate the symptoms of CFS. $(1,3)$

The present study aimed to assess the effectiveness of CBT and RT among teaching professionals with CFS.

Statement Of The Problem:-

A comparative study to assess the effectiveness of cognitive behavioral therapy (CBT) Vs Relaxation therapy(RT) on fatigue among teaching professionals with chronic fatigue syndrome in selected schools ,chennai.

Objectives Of The Study:-

To compare the effectiveness of CBT and RT on level of fatigue among teaching professionals with CFS

\section{Materials and Methods:-}

Design:-Quasi experimental with time series Design

Setting:- The study was conducted at various schools in north and central part of chennai, Tamil Nadu.

Sample size:- 30 Teaching professionals with CFS , who fulfilled the inclusive criteria were taken for study groups and control group with 10 samples in each groups

Sampling technique:- Non-Probability convenient and Purposive Sampling Technique has adopted for the study.

Data collection instrument:- The standerdised instruments were adopted and reproduced with formal permission from the authors and compiled by the investigator with the guidance of exports and review of literature. The tools used for the present study has the following components.

\section{PART I:-}

Self reported semi structured questionnaire for demographic variables:

Age, sex, educational qualification, monthly family income, habitant, religion, marital status, types of family , number of family members, mode of transport, hereditary disease, psychiatric illness, any other illness, attendance to school, gender disadvantage, autonomy

\section{PART II:-}

Krupp LB Fatigue severity scale

It is a self rating instrument, standardized tool used to assess the severity level of fatigue developed by Krupp et al., adopted and reproduced with formal permission from the author.

The reliability of fatigue severity scale and was measured by test and retest method and found the $\mathrm{r}$ value was 0.68 respectively

\section{Intervention:-}

Cognitive behavioral therapy (Study Group I):-

In this present study the investigator used mindfulness integrated cognitive behavioral therapy aimed to modify behavior and beliefs that maintain disability and symptoms of CFS.

Teaching professionals with CFS who fulfilled inclusive and exclusive criteria and assigned to Study group I are given CBT by group therapy using PPT, discussion, home work assignment and revision and demonstration for 8 sessions in 8 weeks duration. Each session lasts for $1 \mathrm{hr}$. Every session begins with home workhome work review and ended with an agreement on home work task which were revealed in daily diaries maintained by the teaching professionals with CFS.The investigator followed detailed session by session therapy plan with modules devised for CBT. Information leaflet supplemented each session and work sheets given for practice in each session. 


\section{Relaxation therapy ( study Group II):-}

The investigator used Jacobson progressive muscle relaxation technique, breathing technique, rapid relaxation skills and guided imagery technique .

Teaching professionals with CFS who fulfilled inclusive and exclusive criteria and assigned to Study group II are given RT by group therapy using PPT, discussion, and demonstration for 8 sessions in 8 weeks duration after completion of total of 7 months of intervention and reinforcement sessions for study group 1(CBT). Each session for RT lasts for $1 \mathrm{hr}$. Every session begins with revision of previous session and ended with return demonstration by the teaching professionals with CFS.

The investigator followed detailed session by session therapy plan with modules devised for RT. Information leaflet supplemented each session.

\section{Control Group:-}

Teaching professionals with CFS in control group given no treatment. .After the data collection period they were given CBT for 4 weeks with information leaflet

\section{Results:-}

Graph1 shows the level of fatigue was almost same in all three groups during pretest but during post 1,2 , and 3 , in study group I and Study group II shows decrease in fatigue level where as none of them were with severe level of fatigue in both Cognitive behavioral therapy and relaxation therapy group. In Control group the level of fatigue reminded the same in pre test and post test $1,2, \quad$ and 3. $\mathbf{N}-=\mathbf{3 0}$

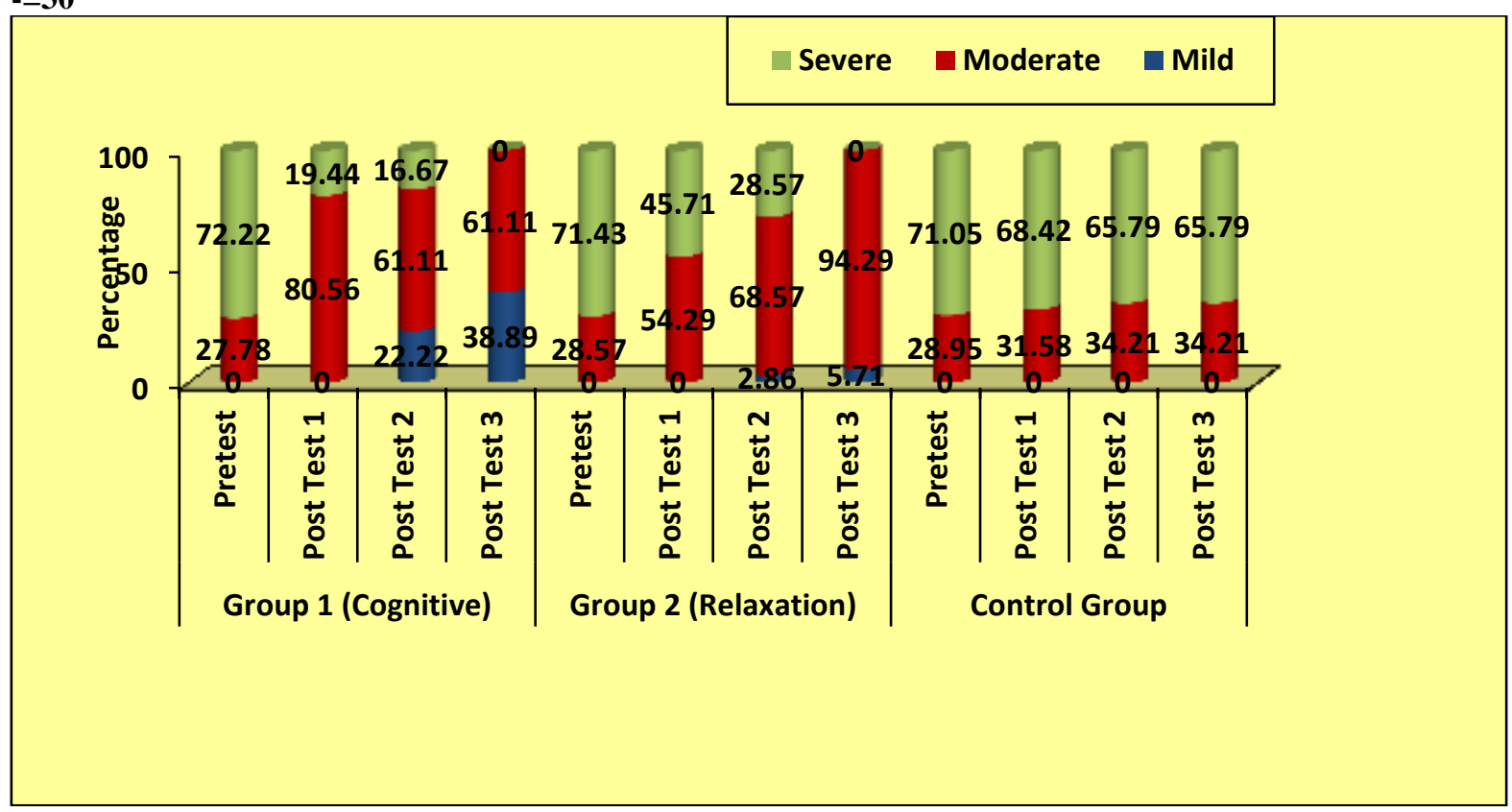

Graph 2:- shows the Comparison of pretest and post tests level of fatigue among teaching professionals with CFS in 
Study Group I (CBT), Study Group II (RT) and Control Group and difference between the scores show highly significant at $p=0.0001$ in all three groups

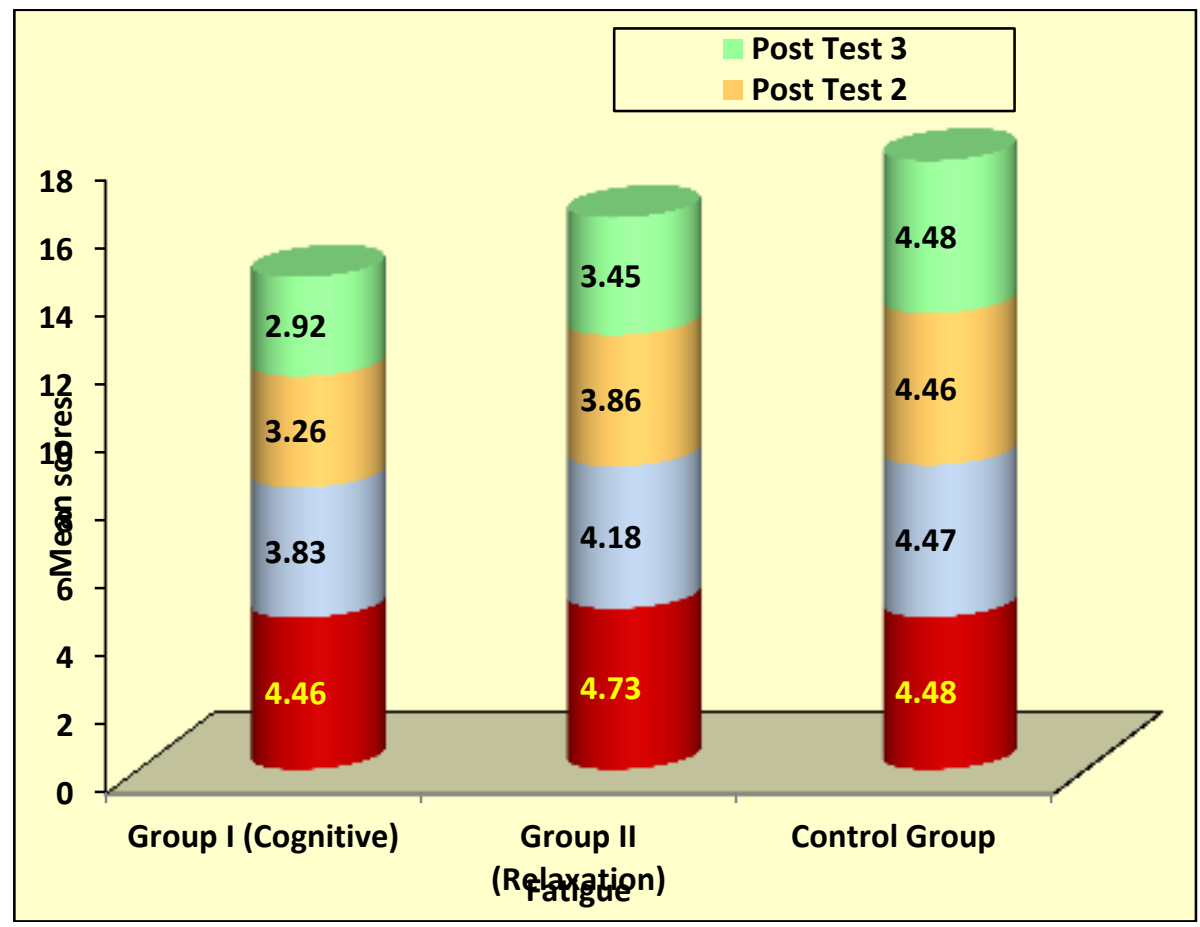

\section{Conclusion:-}

The pilot study revealed that the tool was reliable and practicable .The findings revealed that There is significant improvement in level of fatigue in both CBT group and RT group when compared with control group. When compared to RT group , CBT group shows better improvement in fatigue.

\section{References:-}

1. Balachander, PradyumnaRao,Siddharthsarkar, Shubh Mohan .Chronic fatigue syndrome : A review.Medical journal of Dr.Patil University.2014; Jul-Aug;vol 7 Issue 4.

2. Borah DJ., Chronic fatigue syndrome: a review.AMJ Psychiatry.2003; 160(2):221 -228

3. Brurberg KG, Fønhus M.,(2014) Case definitions for chronic fatigue syndrome/myalgic encephalomyelitis (CFS/ME):a systematic review. BMJ Open. 7;4(2):e003973.

4. Chang-GueSon .,Review of the prevalence of chronic fatigue world wide, The journal of korean Oriental Medicine .2012.vol 33.No.2. 25-33

5. Jason LA, Jordan KM, Richman JA, Rademaker AW, Huang C, McCready W, Frankenberry EL. A communitybased study of prolonged and chronic fatigue. Journal of Health Psychology. 1999;4:9-26

6. Karen lee Richards., (2007) Chronic fatigue syndrome - an update. ActaClin Belg. Jun 17:1-8.

7. Meeus,BerurbergKG, Jane M, McMillan.,(2015) Outcomes of a 6-week cognitive-behavioral and mindfulness group intervention in primary care. FamSyst Health. 2016 Sep;34(3):250-9

8. Williams YJ(1), Jantke RL(1), Jason LA(1).(2014) Chronic Fatigue Syndrome: Case Definitions and Diagnostic Assessment. N Y State Psychol. Winter;26(4):41-45. 